\title{
AVANCES EN LA GENÉTICA DE LA FORMACIÓN DENTAL: UNA REVISIÓN
}

\author{
${ }^{1}$ Johana Verbel Bohórquez, ${ }^{2}$ Oscar Andrés Alfaro Vanegas, ${ }^{3}$ Ethman Ariel Torres Murillo \\ ${ }^{1}$ Odontóloga U. de Cartagena, estudiante Especialización en Ortodoncia U. Santo Tomás Seccional Bucaramanga \\ ${ }^{2}$ Odontólogo U. Nacional de Colombia, estudiante Especialización en Ortodoncia U. Santo Tomás Seccional Bucaramanga \\ ${ }^{3}$ Especialista en Estomatología Pediátrica U. Nacional de Colombia, Esp. en Ortodoncia U. Santo Tomás Seccional Bucaramanga, \\ Magíster en Administración U. Santo Tomás, docente U. Santo Tomás Seccional Bucaramanga
}

Autor responsable de correspondencia: Ethman Ariel Torres Murillo

Correo electrónico: ethman.torres@ustabuca.edu.co

\begin{abstract}
RESUMEN
El desarrollo de las estructuras dentarias es el resultado de un complejo proceso de interacciones recíprocas y secuenciales entre células epiteliales y mesenquimáticas. La organogénesis dental está bajo un estricto control genético donde intervienen factores de crecimiento, de transcripción, moléculas de señalización y proteínas que determinan las posiciones, número y forma de los diferentes dientes. El objetivo de esta revisión fue describir los aspectos embriológicos y moleculares de la formación dental y las anomalías asociadas a un defecto en el patrón genético. Se realizó una búsqueda de literatura en PubMed, Dentistry \& Oral Sciences Source, Science Direct y Scielo. Se concluye que continúan los avances en genética dental que han permitido entender cómo las alteraciones de diferentes genes, factores reguladores y proteínas son los responsables de diversas anomalías dentales. Los avances en la bioingeniería dental podrán resolver muchos de los interrogantes que hoy tenemos. [Verbel N, Alfaro OA, Torres EA. Avances en la genética de la formación dental: una revisión. Ustasalud. 2014; 13(2): 157 - 164]
\end{abstract}

Palabras clave: Genética, Odontogénesis, Bioingeniería, Patología.

\section{ADVANCES IN THE GENETICS OF DENTAL DEVELOPMENT: A REVIEW}

\begin{abstract}
The development of dental structures is the result of a complex process of reciprocal and sequential interactions between epithelial and mesenchymal cells. Tooth organogenesis is under strict genetic control, where involved growth factors, transcription factors, signaling molecules and proteins that determine the positions, number and shape of the individual teeth. The objective of this review was to describe the embryological and molecular aspects of dental development and the anomalies associated with a defect in the gene pattern. A literature search was done in databases such as PubMed, Dentistry \& Oral Sciences Source, Science Direct and Scielo. We concluded that dental genetics have a steady progress, which involves frequent updating and these advances have allowed to understand how changes in different genes, regulatory factors and proteins are responsible for various dental anomalies. The advances in dental bioengineering can solve many of the questions we have today.
\end{abstract}

Keywords: Genetics, Odontogenesis, Bioengineering, Pathology.

Recibido para publicación: 13 de octubre de 2014. Aprobado para publicación: 23 de noviembre de 2014.

\section{INTRODUCCIÓN}

El desarrollo normal del individuo depende de dos grandes factores. Estos son la regulación genética, definida como la influencia del plan genético establecido en el DNA y en el contenido en los cromosomas y la regulación epigenética, que incluye la influencia de los factores externos que inciden en el desarrollo ${ }^{1}$. Ferraris y Muñoz afirman que las células de la cresta neural emigran hacia el mesodermo de los arcos braquiales para dar origen a componen- tes esqueléticos, óseos y cartilaginosos que incluyen los componentes de los tejidos conectivos que formarán el complejo pulpodentinario y los tejidos de sostén del diente como el hueso, ligamento periodontal y cemento ${ }^{2}$.

En el curso del desarrollo de los órganos dentarios humanos aparecen sucesivamente dos clases de dientes: los dientes deciduos y los permanentes. Ambos se originan de la misma manera y presentan una estructura histológica similar. Estos se de- 
sarrollan a partir de brotes epiteliales que, normalmente empiezan a formarse en la porción anterior de los maxilares y avanzan en dirección posterior. Los dientes deciduos inician este proceso en sexta semana de vida intrauterina y los permanentes, a partir del nacimiento. Poseen una forma determinada de acuerdo con el diente al que darán origen y tienen una ubicación precisa en los maxilares. Las dos capas germinativas que participan en la formación de los dientes son, el epitelio ectodérmico, que origina el esmalte y el ectomesenquima que forma los tejidos restantes ${ }^{2}$.

El desarrollo de las estructuras dentarias es el resultado de un complejo proceso de interacciones recíprocas y secuenciales entre células epiteliales y mesenquimáticas. La organogénesis dental está bajo un estricto control genético en el que intervienen factores de crecimiento, factores de transcripción, moléculas de señalización y proteínas que determinan las posiciones, número y forma de los diferentes dientes ${ }^{3}$. El gen MSX-1 es un miembro de la familia de genes homeobox MSX que cumple múltiples funciones durante el proceso de organogénesis. Se expresa en sitios donde son requeridas interacciones epiteliomesénquima y parece tener una función importante en el control del desarrollo craneofacial y dental, como lo demuestran los múltiples estudios en ratones y humanos ${ }^{4}$. Hoy en día, gran parte de las investigaciones están orientadas a interpretar el papel de la genética en la odontogénesis, debido a que se evidencia una alta prevalencia de anomalías dentó-cráneo-maxilo-faciales y se conoce que por medio de la bioingeniería dental se pueden llegar a solucionar defectos y patologías dentales.

El objetivo de la presente revisión consistió en describir los aspectos embriológicos y moleculares de la formación dental, las anomalías asociadas a un defecto en el patrón genético y el papel de las células madre en la reparación celular a través de la bioingeniería dental. Al conocer los procesos de formación dental a nivel molecular será posible la innovación en el desarrollo de nuevos materiales y técnicas en la odontología.

Se realizó una búsqueda de la literatura en las bases PubMed, Dentistry \& Oral Sciences Source, Science Direct y Scielo con los siguientes descriptores del Medical Subject Headings (MeSH): Genetics, Odontogenesis, Bioengineering y Pathology. En las búsquedas se empleó un descriptor a la vez o combinaciones de estos con el operador booleano "AND". La búsqueda se limitó a documentos en idioma inglés y español disponibles en texto completo.

\section{MECANISMOS MOLECULARES IMPLICADOS EN LA ODONTOGÉNESIS}

Diversos autores afirman que alrededor de trescientos genes se encuentran implicados en el proceso de odontogénesis,6; estos juegan un papel importante en la codificación de factores de transcripción, factores de crecimiento, moléculas de la matriz extracelular y en la comunicación celular. Algunas de las vías de señalización genética involucradas en dicha comunicación incluyen el Factor de Crecimiento de Fibroblastos (FGF) y proteínas morfo genéticas (BMP). Munevar y cols. refieren que estos factores de crecimiento y de diferenciación, más el factor neurotrópico derivado de las células gliales (GDNF) están involucrados durante el inicio de la morfogénesis y citó diferenciación? Lidral y Reising le dan importancia al gen MSX1, proteína homeobox no agrupada como vía de señalización común en los eventos presenciados durante la organogénesis, cumpliendo este, un rol importante en el establecimiento de las relaciones epitelio-mesénquima ${ }^{8}$. De modo que la función anormal del gen, ya sea por pérdida de la función o ganancia de esta, puede alterar las vías específicas de señalización que intervienen en el desarrollo dental, lo que resulta no solo en un número anormal de los dientes, sino también en el tamaño o forma anormal de estos.

Por otro lado, Suryadeva y Begum en 2015 mencionan que la formación dental es un proceso genéticamente complicado en el que inicialmente se especifica el tipo, la posición, el tamaño de cada germen dental, y por último, los procesos de formación del esmalte y la dentina ${ }^{9}$. Así mismo, refieren que las interacciones recíprocas entre los tejidos ectodérmicos y ectomesenquimales regulan las etapas clave en el proceso de odontogénesis, denominadas: iniciación, morfogénesis y diferenciación. A continuación se describen cada una de estas etapas ${ }^{9}$.

Etapa de iniciación: el ciclo vital de los órganos dentarios comprende una serie de cambios quími$\cos$, morfológicos y funcionales que comienzan en la sexta semana de vida intrauterina y continúa a lo largo de toda la vida dental. El signo morfológico inicial de formación es la aparición de la lámina dental primaria, definida como una banda gruesa de epitelio que marcará los futuros dientes ${ }^{10}$.

De Coster y cols. mencionan que las placodas dentales se forman a lo largo de la lámina dental primaria y se asemejan morfológicamente, así como en su regulación molecular. Su función consiste en ser el primer centro de señalización dental al secretar varios factores de crecimiento y moléculas de señalización, tales como FGF y BMP, además de 
genes iniciales como los Sonic Hed Hog (SHH). Así mismo, genes P21 y NOTCH que codifican NOTCH 1 , NOTCH 2 y NOTCH3 están regulados en la placoda dental. En el mesénquima, las señales epiteliales inducen la expresión de PX9, PTC, MSX1, MSX2, BMP4 y LEF1. Por otro lado, FGFR1C y FGFR2B se expresan en todo el epitelio dental y oral (Figuras 1 y 2$)^{11}$.

Revuelta, Alberti y cols. y De Coster y cols. afirmaron que en fase de yema, además de observarse el primer crecimiento epitelial dentro del ectomesénquima de los maxilares, el mesénquima dental expresa PAX9, MSX1 y BMP4, los cuales están involucrados en una cascada de señalización recíproca. A su vez, el epitelio dental responderá expresando varios factores de crecimiento y moléculas de señalización, como las proteínas SHH y BMP2 en una región específica del brote epitelial, que será posteriormente llamada nudo del esmalte (Figuras 1 y 2 ) $^{11,12,13}$.

Determinación de la región e identidad dental: el desarrollo de la dentición de los mamíferos puede ser dividido en una secuencia de eventos que comienza con la determinación regional de la dentición. Esto es seguido por la delimitación de las subregiones de las familias dentales, como las regiones incisiva y molar $^{14}$. En estudios de ratones, realizados por Ruch, se observó que los brotes dentales forman en una fila de la lámina dental, un engrosamiento epitelial que marcará el futuro arco dental ${ }^{15}$. Así mismo, afirmó que FGF8 pudo estar implicado en la especificación regional de los lados orales y que en conjunto con BMP determinan la ubicación de la expresión mesénquima de PAX9, un factor de transcripción requerido en el proceso de morfogénesis dental ${ }^{15}$. El FGF8 estimula BMP2 y BMP4 inhiben la expresión PAX9 en el día 10 embrionario a nivel del arco branquial del mesénquima del ratón. De tal forma se sugiere que este antagonismo de señalización determina los sitios o región de brote dental.

Almendárez y cols. mencionaron otros genes que están más restringidos a la lámina dental, como el factor de transcripción PITX2, el gen detrás del síndrome de Rieger caracterizado por agenesia dental y $\mathrm{SHH}$, los cuales se limitan a la formación de brotes dentales ${ }^{16}$.

En relación con la determinación de la identidad dental, Ruch y Sharpe sugieren que el tipo de diente está determinado por la especificidad de las células de la cresta neural ${ }^{15,17}$. En contraste, Mina y Kollar (1987) y Lumsden sugieren a través de un experimento en el que se recombinaron tejidos, que el epitelio dental es el que determina el tipo dental o tiene el poder inductor sobre los tejidos mesenquimales ${ }^{18,19}$.
Jernvall y Thesleff manifiestaron que la proteína BMP4 se expresa en la región anterior del maxilar inferior y la exposición temprana de arcos mandibulares en día nueve y diez de formación dental en ratones a Noggin, un inhibidor eficaz de la señalización de BMP, que da como resultado la transformación de los incisivos a molares ${ }^{20}$. De igual forma, afirman que BMP4 ha demostrado inhibir la expresión del gen homeobox BARX1, el cual se limita al mesénquima molar durante el avance de la morfogénesis y su expresión se estimula por FGF8. Sumado a esto, PITXS1 expresado en el mesénquima mandibular es regulado positivamente por FGF8 y negativamente por BMP4; al eliminar PITXS1, el nivel de BARX1 se reduce en el maxilar inferior y dicha disminución puede explicar la forma de los premolares ${ }^{20}$.

En contraste, Thomas y cols. afirmaron que el desarrollo de molares superiores está determinado por los genes DLX-1 y DLX-2 y el de molares inferiores por DLX-5 y DLX-6. De igual forma, sugirieron que el desarrollo de incisivos se presenta debido a los genes $\mathrm{MSX}^{21}$. De modo que la etapa de iniciación es crítica en determinar el número de dientes que se formarán y garantiza que los diferentes tipos de dientes, incisivos, caninos, premolares y molares se desarrollen en las regiones apropiadas dentro de la cavidad bucal ${ }^{5,6}$. Es así como las diversas investigaciones muestran la necesidad de una relación equilibrada y sinérgica entre el epitelio y mesénquima.

Etapa de morfodiferenciación: este periodo coincide con la etapa de casquete. En él se identifican tres estructuras embrionarias fundamentales para el desarrollo dentario, denominadas órgano del esmalte, esbozo de la papila dentaria y el esbozo del saco dentario. El primero con origen en el ectodermo y los dos últimos con origen en el ectomesenquima. Histológicamente en el órgano del esmalte se pueden distinguir el epitelio externo, retículo estrellado y el epitelio interno compuesto por células cilíndricas bajas que se diferenciarán en ameloblastos ${ }^{5,13}$.

Algunos autores manifiestan que durante la morfogénesis, el control del tamaño y la forma de cada diente dependerá del nudo primario del esmalte. Esta estructura es responsable de regular el crecimiento y los sitios de pliegue epitelial que corresponden directamente con el patrón de las cúspides en la maduración dental ${ }^{22-24}$. En los dientes molares multicúspideos existen nudos del esmalte secundarios que regulan la morfogénesis de cada región cuspídea. Este nudo de células expresa una serie de moléculas de señalización, como SHH, FGF4, BMP4 Y WNT10B y como tal ha sido clasificado como el segundo centro de señalización. La inducción del nudo del esmalte primario puede involu- 
crar señales del mesénquima dental, en particular, el BMP4 (Figuras 1 y 2).

Revuelta afirma que la adición de BMP4 al epitelio oral conduce a una alta regulación de los marcadores de nudo del esmalte, tales como P21. El rango de acción BMP está restringido por la expresión de un antagonista de BMP, conocido como Ectodin. Los ratones knock-out del gen Ectodin se caracterizan por la sobreexpresión de $P 21$, lo que originará nudos de esmalte grande y defectos cuspideos ${ }^{12}$.

El tamaño y la forma del nudo del esmalte primario es la clave para la producción del grado exacto de curvatura del epitelio oral. En los molares, si el nudo de esmalte es demasiado pequeño, como se observa en ratones con mutaciones en Eda o Edrad, se afecta el plegado dental y la colocación de los nudos de esmalte secundarios, conduciendo a un molar con cúspides aplanadas. Por lo tanto, comprometer la señalización a partir del nudo de esmalte primario al modificar su tamaño o forma, implica cambios y defectos en la disposición de los nudos de esmalte secundarios en molares ${ }^{22,25}$.

Etapa de histodiferenciación: en este momento se evidencia la fase de campana, en la cual los ameloblastos y odontoblastos se diferencian y comienzan a establecer el esmalte y la dentina ${ }^{5,6}$. Alvesalo concluyó que los cromosomas sexuales $\mathrm{X}$ y $\mathrm{Y}$ parecen tener efectos directos sobre el crecimiento dental y que el cromosoma $\mathrm{Y}$ promueve el crecimiento del esmalte y dentina, mientras que el cromosoma $\mathrm{X}$ solo influencia el esmalte ${ }^{26}$. El crecimiento y por lo tanto el espesor final del esmalte refleja la actividad secretora de ameloblastos. En contraste, el grosor de la dentina refleja la actividad proliferativa de células pertenecientes al epitelio interno del esmalte. $\mathrm{El}$ autor manifestó que los efectos diferenciales de los cromosomas X y $Y$ en el desarrollo dental se pueden explicar por el dimorfismo sexual observado en las poblaciones humanas, donde los hombres tienden a tener dientes más grandes, que las mujeres.

Por otro lado, el saco dental adopta forma circular y es responsable de la formación de cemento, ligamento periodontal y hueso alveolar propio. En la etapa de campana avanzada los odontoblastos depositan su primera capa de dentina, para que seguidamente los ameloblastos depositen el esmalte sobre esta. El esmalte inicialmente se deposita en el ápice del diente y luego se extiende hasta el cuello. La formación de la raíz no comienza hasta que la formación del esmalte de la corona ha finalizado ${ }^{12 .}$

$\mathrm{El}$ asa cervical estará formada por la unión del epitelio externo e interno, se mantiene en continuo crecimiento dental y constituye una parte del epi- telio de las células madre adultas. En un continuo crecimiento de los dientes el asa cervical se someterá a una modificación estructural que formará la parte inicial de la raíz. El núcleo central desaparece dejando solo una doble capa de epitelio basal conocida como la vaina epitelial de Hertwig's. Esta direccionará el crecimiento de la raíz y dará lugar a una red de células epiteliales que cubren la raíz conocida como los restos epiteliales de Mallases. Ambos, tanto la vaina epitelial de Hertwig's y los restos epiteliales de Mallases se cree tienen una capacidad límite de crecimiento ${ }^{27,28}$.

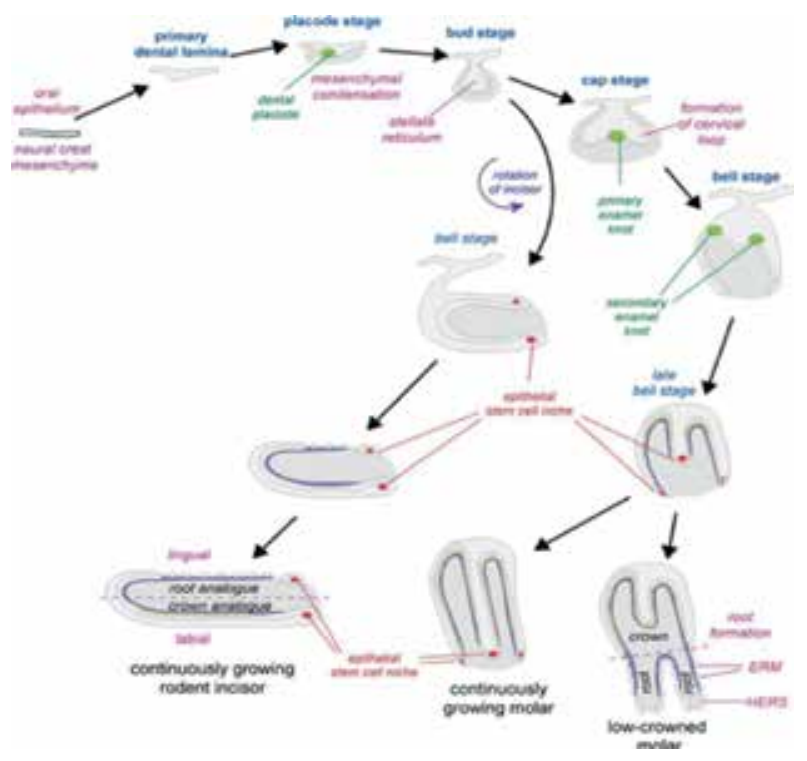

Figura 1. Patrones durante la morfogénesis dental ${ }^{20}$.

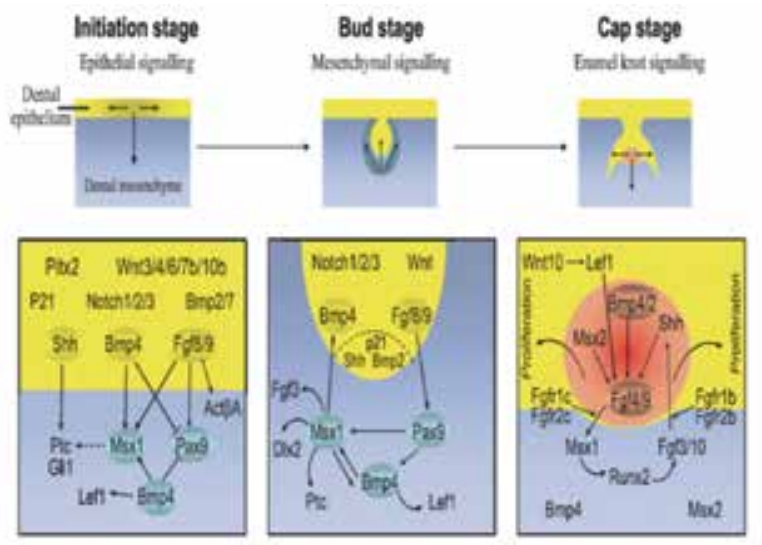

Figura 2. Genética dental ${ }^{11}$.

\section{Desordenes dentales}

Parece existir una interrelación genética en la determinación de algunas de las anomalías. Un mismo defecto genético puede originar diferentes manifestaciones fenotípicas que incluyen agenesias, microdoncias, ectopias y retraso en el desarrollo dental. 
Las anomalías dentarias se expresan con distintos grados de severidad, representadas desde el atraso cronológico en la odontogénesis hasta la ausencia completa del germen dentario o agenesia. Por lo tanto, cuando una determinada irregularidad muestra una prevalencia aumentada en familias de pacientes afectados, se le atribuye a la genética una influencia predominante en la etiología del problema ${ }^{29}$.

Entre las anomalías más frecuentes y que cuentan con respaldo suficiente sobre la intervención de la genética en su formación están:

Agenesia dentaria: es la anomalía más común de desarrollo de la dentición humana, se produce en aproximadamente el $25 \%$ de la población. La genética probablemente representa el factor etiológico primordial de las agenesias dentarias. Recientemente se identificó una mutación en el gen MSX1, en una familia con agenesia de todos los segundos premolares y terceros molares. El gen MSX1 está ubicado en el cromosoma 4p16, regula la señalización e interacción de tejidos durante las etapas tempranas del desarrollo dental y es el responsable de un patrón específico de herencia de agenesia dental autosómica dominante y así mismo, parece ser el responsable de la agenesia de segundos premolares y terceros molares ${ }^{3}$.

El PAX9, otro de los genes implicados, pertenece a una familia de factores de transcripción presentes en los mamíferos. Es un regulador importante de la organogénesis, puede actuar como desencadenante de la diferenciación celular o como mantenedor de la pluripotencialidad de las poblaciones de células madre durante el desarrollo. Las mutaciones del PAX9 se asocian con la agenesia dental aislada familiar y con defectos en el desarrollo, que principalmente involucran los dientes posteriores más dístales ${ }^{3}$.

Por otro lado, Vieira y cols. afirman que el locus del gen TGFA está asociado con agenesia dental en la población estudiada, en especial en los casos de ausencia de incisivos. Comentan que el TGFA se expresa durante el desarrollo craneofacial y los ratones que presentan deficiencia de TGFA presentan anomalías en los ojos y el pelo, pero no en los dientes ${ }^{23}$.

\section{Síndromes asociados a la agenesia}

Síndrome Witkop "de dientes y uñas»: es también una displasia ectodérmica, caracterizada por hipodoncia u oligodoncia y por disgenesia ungueal. Los dientes presentes pueden ser coniformes, con raíces cortas o molares taurodontiformes. Puede afectar a la dentición primaria. La herencia es autosómica dominante. Las uñas son hipoplásicas y con forma de cuchara, principalmente las de los pies. La expresividad es muy variable. Se ha identificado una mutación con pérdida de sentido en el homeobox de MSX1 como responsable de este desorden ${ }^{6 .}$

Displasia ectodérmica anhidrótica (DEA): las displasias ectodérmicas son un conjunto de aproximadamente 150 afecciones que incluyen alteraciones de al menos dos de las estructuras derivadas del ectodermo como el pelo, la piel, las uñas y los dientes. La DEA se caracteriza por hipohidrosis, hipotricosis e hipodoncia. Se observa una oligodoncia grave en la dentición decidua y permanente. Los dientes presentes suelen ser coniformes, puede haber taurodontismo. Las mutaciones puntuales, deleciones o translocaciones que afectan al gen ED1 (=EDA) en Xq12-q13.1, producen la enfermedad ${ }^{6}$.

Síndrome de Rieger tipo I: se caracteriza por hipodoncia o forma cónica de los incisivos mandibulares y ocasionalmente agenesia de premolares, malformación de cámara anterior del ojo que ocasiona ceguera y anomalías umbilicales. La herencia es autosómica dominante con penetrancia completa y expresividad variable. Las mutaciones responsables de esta malformación se encontraron en el gen PITX2 y SHH SH. $^{3,6}$

Deficiencia He-Zhao: la herencia es autosómica dominante, con una penetrancia estimada de $88 \%$ y de expresividad muy variable. La dentición primaria es normal; el número de piezas permanentes ausentes es muy variable, implica principalmente a los terceros molares, segundos premolares e incisivos laterales superiores y puede alcanzar a toda la dentición. Los principales genes candidatos responsables de la alteración son Dkk-1 que codifica una proteína antagonista de la señalización por WNT; PRKG1B que produce una proteinquinasa GMP-dependiente. Actualmente, se desarrollan estudios de secuenciación para detectar mutaciones en estos genes ${ }^{6 .}$

Dentinogénesis imperfecta (DI): se describe como una forma localizada de displasia mesodérmica observada en histodiferenciación y corresponde a un defecto congénito que involucra dientes deciduos y permanentes. Las características radiológicas de la DI incluyen coronas bulbosas con raíces cortas, obliteración progresiva de la cámara pulpar. Histológicamente los túbulos dentinarios son irregulares y más grandes en diámetro ${ }^{31}$.

Defectos de dentina se producen como característica en un número de síndromes, incluyendo la osteogénesis imperfecta (OI), el síndrome de EhlersDanlos (EDS), calcinosis tumoral y el raquitismo hipofosfatémico. La mutación en el gen DSPP es la 
causa de este defecto. El gen se encuentra localizado en 4q21.3 en un clúster de genes de la matriz de dentina y hueso. DSPP codifica tanto la Dentina Sialoproteína (DSP) y la Dentina Fosfoproteína (DPP). DSP Y DPP tienen diferentes roles en dentinogénesis. DPP sirve como un nucleador de la mineralización e induce la formación de apatita ${ }^{31,32}$.

Apiñamiento dental: esta es una característica frecuente de maloclusión dentaria. Es la reducción en el perímetro del arco que se puede manifestar como cierre del espacio, rotación o movimiento de los dientes ${ }^{33}$. Se sugieren factores genéticos en la contribución del apiñamiento dental. Estudios recientes proporcionan evidencia de la asociación entre los genes EDA y XEDAR y el apiñamiento dental ${ }^{34}$. Diversos estudios han proporcionado evidencia de las asociaciones entre los factores genéticos y los rasgos dentales comunes, como el tamaño de los dientes ${ }^{35,36}$.

Amelogénesis imperfecta: es un grupo clínica y genéticamente heterogéneo de trastornos caracterizados por un desarrollo defectuoso del esmalte dental debido a la hipoplasia o hipomineralización. A pesar que existen pocos datos sobre su prevalencia, la proporción se encuentra entre $1: 14.000$ y $1,4: 1.000^{37}$. Los fenotipos de amelogénesis imperfecta varían ampliamente según el gen específico involucrado, la ubicación y el tipo de mutación. Los defectos en el esmalte en la amelogénesis imperfecta se pueden dividir en hipoplásico caracterizado por un esmalte delgado que no crece en la longitud correcta e hipomineralizado en el que el esmalte no presenta un grosor o ancho adecuado. La amelogénesis imperfecta puede ser heredada de forma autosómica dominante, autosómica recesiva o ligada al cromosoma $\mathrm{X}^{38}$.

La formación del esmalte requiere la expresión de múltiples genes que transcriben proteínas de la matriz y proteinasas necesarias para controlar el proceso de crecimiento de los cristales de hidroxiapatita y la mineralización. Las mutaciones de genes asociados a amelogénesis imperfecta identificados hasta la fecha implican dos moléculas de la matriz extracelular del esmalte: amelogenina y enamelina. Amelogenina, el producto de AMELX Xq22 y AMEL Yp11Y, genes que constituyen $90 \%$ de la matriz orgánica en el desarrollo de esmalte y se consideran críticos para el espesor y estructura normal del esmalte. Enamelina, el producto proteico del gen ENAM en el cromosoma 4q21, está presente en cantidades relativamente pequeñas y se somete a una serie de escisiones proteolíticas para generar varios polipéptidos que se cree que participan en la nucleación y extensión de los cristales y la re- gulación del hábito cristalino. Además de ENAM y AMELX, un número de otros genes importantes para la formación del esmalte fueron identificados y propuestos como candidatos para amelogénesis imperfecta e incluyen ameloblastina (AMBN en 4q21), tuftelina, (TUFT1 en el cromosoma 1q21) y dos genes de proteasas relacionados con el esmalte: enamelisina (MMP20 en 11q22-q23) y calicreína 4 (KLK4 en 19q13). Se cree que estas proteinasas regulan el procesamiento de la proteína matriz del esmalte que define en última instancia la estructura y la composición de esmalte ${ }^{38}$.

Por otro lado, Wright y cols. (2015) realizaron una consulta en On Line Mendelian Inheritance in Man (OMIM) para determinar el número y la diversidad funcional de los genes asociados con defectos hereditarios del esmalte y las vías moleculares involucradas. Estos afirmaron que a pesar de la diversidad de defectos moleculares, el fenotipo más común que se describe en la consulta es la hipoplasia del esmalte $^{39}$. No es de sorprender que las alteraciones en una variedad de vías puedan conducir a un fenotipo de hipoplasia del esmalte dada la sensibilidad y la exquisita regulación de los procesos de amelogénesis. Existe un extenso número de síndromes asociados a defectos en el esmalte, en el que no solo se ve afectado el fenotipo de esmalte sino también tejidos u órganos del cuerpo humano como el cerebro, los ojos, riñón, la piel, según la condición.

Finalmente, es importante resaltar el papel de la genética molecular en la regeneración dental con células madre al ser esta una alternativa más biológica y fisiológica en comparación con los tratamientos dentales actuales para la solución de anomalías dentales. Estas células residen en un lugar específico llamado nicho y gran parte de ellas se encuentran en el complejo dental ${ }^{40}$.

Magallanes y cols. refieren que la investigación en células madre se considera como una de las líneas de investigación más importante en la reparación, regeneración de tejidos y órganos como el tejido dental y periodontal. Además afirman que son células no especializadas que se renuevan durante largos periodos de tiempo por división celular y son capaces de diferenciarse en células con funciones especiales a través de un estímulo adecuado y de esta forma podrán ser utilizadas a futuro en los tratamientos ortodónticos ${ }^{41}$. Así mismo, Nakao y Tsuji, y Bluteau y cols. afirmaron que la medicina regenerativa promete nuevas técnicas terapéuticas para la reparación y el reemplazo de tejidos y órganos que han perdido funciones debido al envejecimiento, enfermedad, daños y defectos congénitos (Figura 3) 32,43. $^{4}$. 


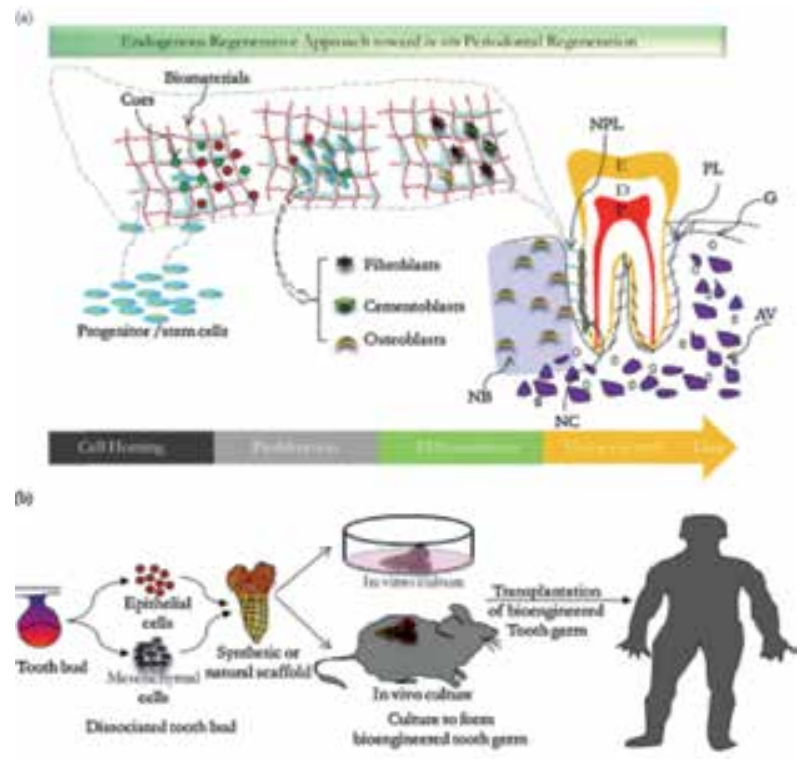

Figura 3. Ingeniería del tejido dental. Tomado de: Abou Neel et al. Tissue engineering in dentistry. J Dent. 2014;42(8):915-928.

\section{Conclusiones}

El desarrollo de las estructuras dentales está mediado por la interacción de procesos biológicos, morfológicos y genéticos, necesarios para una adecuada diferenciación de los tejidos. Estas interacciones tienen como genes responsables, factores de transcripción, mecanismos de señalización molecular, factores de crecimiento que regulan la organogénesis. Los genes Homeobox MSX1, PAX9 son esenciales en procesos como la odontogénesis, palatogénesis y el desarrollo del complejo craneofacial. Una función anormal de estos alteraría vías de señalización que intervienen en los distintos procesos.

Es por eso que se pueden presentar diversas anomalías dentales que alteran forma, estructura, número, tamaño y color dental y es la agenesia dental la más común del desarrollo de la dentición humana. La bioingeniería propone alternativas futuras para que In vivo admita la regeneración y reparación tisular al permitir opciones biológicas de tratamiento en anomalías dento-maxilo-craneo-faciales.

\section{BIBLIOGRAFÍA}

1. Ferraris MEG, Muñoz AC. Histologia, embriologia e ingeniera tisular bucodental/histology, embryology and oral tissue engineering. 3a ed. Buenos Aires: Ed. Médica Panamericana; 2010. $468 \mathrm{p}$.

2. Ferraris MEG, Muñoz AC. Histología y embriología bucodental. 2a ed. Madrid: Editorial Médica Panamericana; 2002.

3. Arboleda LÁ, Echeverri J, Restrepo LÁ, Marín ML, Vásquez G, Gómez JC, et al. Agenesia dental. Revisión bibliográfica y reporte de dos casos clínicos. Rev Fac Odontol Univ Antioq. 2009;18(1):47-54.
4. Ortiz MA, Mejía CA. Actividad de los genes tipo MSX-1 durante el desarrollo craneofacial. Revista Estomatologia. 2007;15(1):34-38.

5. Townsend G, Bockmann M, Hughes T, Brook A. Genetic, environmental and epigenetic influences on variation in human tooth number, size and shape. Odontology / the Society of the Nippon Dental University. 2012;100(1):1-9.

6. Fusé FJK. Agenesias dentarias: en busca de las alteraciones genéticas responsables de la falta de desarrollo. Med Oral Patol Oral Cir Bucal. 2004;9(5):385-95.

7. Munévar N, Becerra A, Bermúdez C. Aspectos celulares y moleculares de las células madres involucrados en la regeneración de tejidos con aplicaciones en la práctica clínica odontológica. Acta Odontol Venez. 2008;46(3):1-12.

8. Lidral A, Reising B. The role of MSX1 in human tooth agenesis. J Dent Res. 2002;81(4):274-8.

9. Suryadeva S, Khan MB. Role of homeobox genes in tooth morphogenesis: a review. Journal of clinical and diagnostic research: J Clin Diagn Res. 2015;9(2):12-18.

10. Jussila M, Thesleff I. Signaling networks regulating tooth organogenesis and regeneration, and the specification of dental mesenchymal and epithelial cell lineages. Cold Spring Harb Perspect Biol. 2012;4(4):1-13.

11. De Coster P, Marks L, Martens L, Huysseune A. Dental agenesis: genetic and clinical perspectives. J Oral Pathol Med. 2009;38(1):1-17.

12. Revuelta R. La cavidad bucal del nacimiento a la infancia: Desarrollo, patologías y cuidados. Perinatol Reprod Hum. 2009;23(2):82-89.

13. Albertí L, Sarabia MM, Martínez S, Méndez MJ. Histogénesis del esmalte dentario. Consideraciones generales. Revista Archivo Médico de Camagüey. 2007;11(3):1-11.

14. Maas R, Bei M. The genetic control of early tooth development. Crit Rev Oral Biol Med. 1997;8(1):4-39.

15. Ruch JV. Odontoblast commitment and differentiation. Biochem Cell Biol. 1998;76(6):923-38.

16. Almendárez J, Serna J, Cepeda P, Romero D, Koga W, Takane M. Síndrome de Axenfeld-Rieger: Hallazgos clínicos, ecográficos y en ultrabiomicroscopia. Rev Mex Oftalmol. 2015;89(3):194-199.

17. Sharpe PT. Homeobox genes and orofacial development. Connect Tissue Res. 1995;32(1-4):17-25.

18. Mina M, Kollar E. The induction of odontogenesis in nondental mesenchyme combined with early murine mandibular arch epithelium. Arch Oral Biol. 1987;32(2):123-7.

19. Lumsden A. Spatial organization of the epithelium and the role of neural crest cells in the initiation of the mammalian tooth germ. Development. 1988;103 Suppl:155-69.

20. Jernvall J, Thesleff I. Reiterative signaling and patterning during mammalian tooth morphogenesis. Mech Dev 2000;92(1):19-29.

21. Thomas BL, Tucker AS, Ferguson C, Qiu M, Rubenstein JL, Sharpe PT. Molecular control of odontogenic patterning: positional dependent initiation and morphogenesis. Eur J Oral Sci. 1998;106(S1):44-7.

22. Caton J, Tucker AS. Current knowledge of tooth development: patterning and mineralization of the murine dentition. J Anat. 2009;214(4):502-15.

23. Vieira A, Meira R, Modesto A, Murray J. MSX1, PAX9, and TGFA contribute to tooth agenesis in humans. J Dent Res. 2004;83(9):723-7. 
24. Pereira TV, Salzano FM, Mostowska A, Trzeciak WH, Ruiz-Linares A, Chies JA, et al. Natural selection and molecular evolution in primate PAX9 gene, a major determinant of tooth development. Proc Natl Acad Sci U S A. 2006;103(15):5676-81.

25. Catón J, Luder H-U, Zoupa M, Bradman M, Bluteau G, Tucker AS, et al. Enamel-free teeth: Tbx1 deletion affects amelogenesis in rodent incisors. Dev Biol. 2009;328(2):493505.

26. Alvesalo L. Human sex chromosomes in oral and craniofacial growth. Arch Oral Biol. 2009;54:S18-S24.

27. Ten Cate AR, Ochoa E. Histología oral: desarrollo, estructura y función. 2da ed. Buenos Aires: Editorial Médica Panamericana; 1986 . p. 80-106.

28. Thesleff I, Tummers M. Tooth organogenesis and regeneration. StemBook [Internet]. Cambridge (MA): Harvard Stem Cell Institute; 2008-2009.

29. Garib DG, Alencar BM, Ferreira FV, Ozawa TO. Associated dental anomalies: The orthodontist decoding the genetics which regulates the dental development disturbances. Dental Press J Orthod. 2010;15(2):138-57.

30. Jugessur A, Lie RT, Wilcox AJ, Murray JC, Taylor JA, Saugstad OD, et al. Variants of developmental genes (TGFA, TGFB3, and MSX1) and their associations with orofacial clefts: A case parent triad analysis. Genet Epidemiol. 2003;24(3):230-9.

31. Devaraju D, Devi BY, Vasudevan V, Manjunath V. Dentinogenesis imperfecta type I: A case report with literature review on nomenclature system. J Oral Maxillofac Pathol. 2014;18(Suppl 1):S131-4.

32. Pardo RA, Castillo S, Vieira AR. Estudio genético de una familia chilena con tres fenotipos dentales diferentes. Rev Méd Chile. 2006;134(12):1541-8.

33. Vego L. A longitudinal study of mandibular arch perimeter. Angle Orthod. 1962;32(3):187-92.

34. Ting TY, Wong RW, Rabie AB. Analysis of genetic polymorphisms in skeletal Class I crowding. Am J Orthod Dentofacial Orthop. 2011;140(1):e9-15.
35. Yamaguchi T, Kawaguchi A, Kim Y-I, Haga S, Katayama $\mathrm{K}$, Ishida $\mathrm{H}$, et al. The role of polymorphisms associated with early tooth eruption in dental and occlusal traits in East Asian populations. Koren J Orthod. 2014;44(2):96102.

36. Lee WC, Yamaguchi T, Watanabe C, Kawaguchi A, Takeda M, Kim YI, et al. Association of common PAX9 variants with permanent tooth size variation in non-syndromic East Asian populations. J Hum Genet. 2012;57(10):654-9.

37. Hunter L, Addy LD, Knox J, Drage N. Is amelogenesis imperfecta an indication for renal examination? Int J Paediatr Dent. 2007;17(1):62-5.

38. Hart P, Hart T, Michalec M, Ryu O, Simmons D, Hong S, et al. Mutation in kallikrein 4 causes autosomal recessive hypomaturation amelogenesis imperfecta. J Med Genet. 2004;41(7):545-9.

39. Wright JT, Carrion IA, Morris C. The molecular basis of hereditary enamel defects in humans. J Dent Res. 2015;94(1):52-61.

40. Jasso CGR, Barrios MBCA. Bioingeniería dental ¿El futuro de la terapia en odontología? Revista ADM. 2011;68(4):169-74.

41. Magallanes F, Rodríguez BC, Pérez MÁ. Aislamiento y caracterización parcial de células madre de pulpa dental. Rev Odon Mex. 2010;14(1):15-20.

42. Nakao K, Tsuji T. Dental regenerative therapy: Stem cell transplantation and bioengineered tooth replacement. Japanese Dental Science Review. 2008;44(1):70-5.

43. Bluteau G, Luder H, De Bari C, Mitsiadis T. Stem cells for tooth engineering. Eur Cell Mater. 2008;16:1-9.

\section{Correo electrónico de los autores:}

johyv_106@hotmail.com oaalfarov@unal.edu.co ethmant@yahoo.com 